\title{
Morfologia, ultraestrutura e morfometria do tegumento da paca (Cuniculus paca Linnaeus, 1766) criada em cativeiro ${ }^{1}$
}

\author{
José G.M.P. Isola²*, Paola C. Moraes ${ }^{3}$, Sheila C. Rahal ${ }^{4}$ e Márcia R.F. Machado²
}

\begin{abstract}
Isola J.GM.P., Moraes P.C., Rahal S.C. \& Machado M.R.F. 2013. [Morphology, ultrastructure and morphometry of the tegument of paca (Cuniculus paca Linnaeus, 1766) raised in captivity.] Morfologia, ultraestrutura e morfometria do tegumento da paca (Cuniculus paca Linnaeus, 1766) criada em cativeiro. Pesquisa Veterinária Brasileira 33(5):674-682. Departamento de Morfologia e Fisiologia Animal, Universidade Estadual Paulista, Via de Acesso Prof. Paulo Donato Castellane s/n, Jaboticabal, SP 14884-900, Brazil. E-mail: jgmpi@ig.com.br

Considering the lack of detailed information about the morphology of paca, which is the second largest rodent of Brazilian's fauna, with excellent meat quality and, due to the importance of the common integument, we described the morphology, ultrastructure and morphometry of the skin of eight pacas (Cuniculus paca), males and females, through comparative analysis of skin's segments of the cervical, dorsal and medial carpal portions. Macroscopic characteristics of the coat were studied. Part of the segments of cutaneous regions was analyzed by light microscopy, and the other part by scanning electron microscopy. We measured the thickness of dermis, epidermis, stratum corneum, the profiles of the collagen fibers of reticular dermis and the area of filled sebaceous gland cells. The results were analyzed by descriptive statistics and " $\mathrm{T}$ " test $(\mathrm{p}<0.001)$. The color of the coat is reddish brown with bristles arranged in groups. The architecture of the skin and skin appendages resembles those of mammals in general, although there are no sweat glands. According to the morphometric analysis, this study shows differences of the skin architecture between male and female pacas and also between various body regions in the same animal.
\end{abstract}

INDEX TERMS: Paca, Cuniculus paca, rodents, integument, cutaneous glands, histology, scanning electron microscopy.

RESUMO.- Considerando-se a falta de informações detalhadas sobre a morfologia da paca, sendo o segundo maior roedor da fauna brasileira, de excelente qualidade de carne e, dada a importância do tegumento comum, inclusive para o bom manejo em cativeiro, e até mesmo estudos como uma opção de animal de experimentação, descreveu-se a morfologia, morfometria e a ultraestrutura da pele de oito pacas

\footnotetext{
${ }^{1}$ Recebido em 28 de novembro de 2012.

Aceito para publicação em 4 de abril de 2013.

${ }^{2}$ Departamento de Morfologia e Fisiologia Animal, Universidade Estadual Paulista "Julio de Mesquita Filho" (Unesp), Campus Jaboticabal, Via de Acesso Prof. Paulo Donato Castellane s/n, Jaboticabal, SP 14884-900 Brasil. *Autor para correspondência: jgmpi@ig.com.br

${ }^{3}$ Departamento de Clínica e Cirurgia de Pequenos Animais, Unesp, Campus Jaboticabal, Via de Acesso Prof. Paulo Donato Castellane s/n, Jaboticabal, SP.

${ }^{4}$ Departamento de Cirurgia e Anestesiologia Veterinária, Unesp, Campus Botucatu, Distrito de Rubião Junior s/n, Botucatu, SP 18618-970, Brasil.
}

(Cuniculus paca) machos e fêmeas, mediante a análise comparativa de segmentos cutâneos das regiões cervical, dorsal e medial do carpo. Observaram-se macroscopicamente as características da pelagem. Parte dos segmentos das regiões cutâneas foi analisada à microscopia de luz e parte, à microscopia eletrônica de varredura. Mensuraram-se as espessuras da derme, epiderme, camada córnea, perfis das fibras de colágeno da derme reticular e a área dos perfis das células das glândulas sebáceas repletas. Analisaram-se os resultados pela estatística descritiva e teste " $\mathrm{T}$ " $(\mathrm{p}<0,001)$. A coloração da pelagem da paca é castanho avermelhado com cerdas organizadas em grupos. A arquitetura da cútis e os anexos cutâneos se assemelham aos dos mamíferos em geral, embora haja ausência de glândulas sudoríparas. De acordo com a analise morfométrica, pôde-se inferir que a arquitetura da cútis de pacas machos e fêmeas apresenta diferenças quando comparada entre os sexos e também em um mesmo animal, diferenciando-se entre diversas regiões corpóreas. 
TERMOS DE INDEXAÇÃO: Paca, Cuniculus paca, roedores, tegumento, glândulas cutâneas, histologia, microscopia eletrônica de varredura.

\section{INTRODUÇÃO}

A espécie Cuniculus paca, popularmente chamada de paca, depois da capivara, é considerada o maior roedor brasileiro (Eisenberg 1989). Animais de porte médio, vivem em áreas cobertas com vegetação alta, próximos aos rios ou riachos, pois tem o costume de mergulhar, principalmente quando se sentem ameaçados. Sua pelagem, assim como de outros animais selvagens, é característica e lhes conferem proteção no ambiente em que vivem (Glover 1940, Lekagul \& McNeely 1977). Possuem hábitos noturnos, abrigam-se em tocas, geralmente situadas em meio a rochas ou raízes, onde passam o dia todo, saindo apenas à noite para se alimentarem de vegetais e frutos diversos (Mondolfi 1972, Silva 1994).

Os roedores, como é o caso da paca, em virtude de apresentarem aspectos característicos tais como, tamanho adequado, preço acessível e curto período de prenhez, juntamente com os lagomorfos, foram considerados por Björkman et al. (1989), grupos de animais experimentais "ad hoc". Também as observações de Hamlett \& Rasweiler IV (1993) devem ser relevadas, ao evidenciarem a necessidade da busca de novos exemplares, entre os animais, para serem utilizados como modelos experimentais adequados e assim colaborarem com o desenvolvimento de pesquisas vitais tanto ao homem quanto a outras espécies.

Deve-se salientar que em estudo sobre a criação comercial de paca para o consumo de sua carne, Lourenço et al. (2008) descreveram, com muita propriedade, que esta atividade representa uma alternativa de conservação da espécie ao gerar o aumento de seu estoque populacional e também atuar como forma de diminuição da pressão sobre sua caça e, consequentemente tráfico, além de contribuir com a conservação das áreas marginais às florestas ou reservas.

0 estudo do tegumento dos animais pode refletir o modo de vida de cada espécie, pois a cútis está em contato direto com o meio ambiente e as propriedades deste órgão podem variar em relação ao local em que cada animal vive (Klauer et al. 1997), além do mais, a morfologia do tegumento pode ser um indicador mais confiável sobre o habitat e o modo de vida dos animais do que a sua própria filogenia (Daly \& Buffenstein 1998).

A arquitetura básica da cútis é semelhante em todos os mamíferos, mas existem diferenças entre as diferentes espécies animais; entre indivíduos da mesma espécie, independente do sexo e entre as diferentes regiões do corpo de um mesmo indivíduo (Mayer 1952, Montagna 1967, Pereira et al. 1980, Banks 1992, Hib 2003, Azzi et al. 2005, Yabuki et al. 2007, Junqueira \& Carneiro 2008, Reis et al. 2008, Souza et al. 2009).

Como componente da fauna silvestre brasileira e de excelente qualidade de carne, a paca, que até o momento não teve sua morfologia amplamente estudada, merece mais atenção dos morfologistas, pois existem ainda grandes lacunas quanto à descrição específica de muitos de seus aspectos anatômicos. Assim, diante da importância da pele, considerada um dos maiores órgãos do organismo dos vertebrados e que se caracteriza por ser uma estrutura muito mais complexa do que aparenta, apresentando, dentre várias funções, principalmente a de proteção do organismo das ameaças externas físicas, além de exercer atividades imunológicas, de termorregulação, nervosas e metabólicas (Chuong \& Homberger 2003, Albers \& Davis 2007) e de extrema importância para o bom manejo em cativeiro, ou até mesmo estudos como uma opção de animal de experimentação, objetivou-se com este trabalho descrever a morfologia, morfometria e a ultraestrutura da pele da paca, mediante a análise comparativa de segmentos cutâneos das regiões cervical, dorsal e medial do carpo.

\section{MATERIAL E MÉTODOS}

A metodologia adotada neste estudo foi aprovada pela Comissão de Ética no Uso de Animais (CEUA), da Faculdade de Ciências Agrárias e Veterinárias, Campus de Jaboticabal da Universidade Estadual Paulista "Júlio de Mesquita Filho" (FCAV-Unesp), sob o protocolo no. 008621-09.

Foram utilizadas oito pacas adultas, sendo quatro fêmeas e quatro machos, excedentes do plantel do Setor de Animais Silvestres do Departamento de Zootecnia da Faculdade de Ciências Agrárias e Veterinárias de Jaboticabal, Unesp. Este criatório é registrado junto ao Instituto Brasileiro do Meio Ambiente e dos Recursos Naturais Renováveis (IBAMA), como criatório de espécimes da fauna brasileira para fins científicos, número do cadastro 482508, emitido em 3.3.2009.

Para a realização da análise morfológica do tegumento das pacas, procedeu-se exame macroscópico, microscópico e a microscopia eletrônica de varredura das seguintes regiões cutâneas: cervical, torácica e medial do carpo, tanto do antímero direito quanto do esquerdo.

Para o estudo macroscópico, analisaram-se as regiões cutâneas estabelecidas, observando-se os tipos e intensidade dos pêlos encontrados, sua coloração e presença de outra característica peculiar. Para a documentação foram feitos registros fotográficos.

Imediatamente após a eutanásia dos animais, foram colhidos segmentos das regiões cutâneas em questão e essas amostras foram divididas; parte delas foi preparada para análise comparativa à microscopia de luz e parte, processada para observação à microscopia eletrônica de varredura.

0 material destinado a análise à microscopia de luz foi fixado em solução de McDowell e, em seguida, processado para a inclusão em parafina plástica (HISTOSEC ${ }^{\circledR}$ - Merck, Brasil). As preparações histológicas foram obtidas mediante cortes semi-seriados de $5 \mu \mathrm{m}$, respeitando-se intervalo de $100 \mu \mathrm{m}$ entre eles, obtendo-se total de cinco cortes por região para que se procedesse a análise morfométrica do material. Para a inclusão do material foi realizada a rotina histológica convencional (Behmer et al. 1976).

Os cortes foram corados com Hematoxilina-eosina, além da reação do Acido periódico e Shiff, para possibilitar especificamente a visibilização da membrana basal e a ocorrência secreção glandular, e consequente identificação destas estruturas.

As preparações histológicas foram analisadas e imagens capturadas em fotomicroscópio (Leica, DM5000 B) acoplado a câmera digital (Leica DFC300 FX), para a documentação. Para a realização das análises morfométricas, foi utilizado o software de análise Leica Qwin $®$ (Leica Image Processing and Analysis Software - Leica Microsystem Ltd, Heerbrugg, Switzerland).

Cada lâmina continha cinco cortes, e em cada um, as estruturas foram mensuradas em três campos distintos, totalizando dez medidas de cada parâmetro avaliado, por corte. Assim, obtive- 
ram-se cinquenta medidas de cada parâmetro, para cada uma das regiões cutâneas analisadas de cada animal.

Nas amostras cutâneas das regiões cervical, torácica e medial do carpo foram avaliados os seguintes parâmetros: espessura da derme; espessura da epiderme; espessura da camada córnea; espessura dos perfis das fibras de colágeno da região da derme reticular e a área dos perfis das células das glândulas sebáceas repletas de conteúdo, neste caso visando avaliar sua capacidade de armazenamento.

Mediante aplicação da estatística descritiva (programa MINITAB versão 14) calcularam-se, dos parâmetros analisados, os valores das médias, dos desvios padrão e seus intervalos de confiança a 95\%, buscando-se caracterizar morfométricamente o tegumento de pacas machos e fêmeas adultas. Para o estabelecimento de comparações aplicou-se o teste "T" ( $\mathrm{p}<0,001)$ nos valores encontrados para os parâmetros mensurados entre as diferentes regiões estudadas, bem como para os diferentes sexos.

Para o estudo ultraestrutural, as amostras colhidas foram fixadas em solução de glutaraldeído a 2,5\% por 24 horas, lavadas em

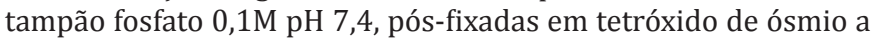
$1 \%$ por duas horas, lavadas novamente em tampão fosfato, desidratadas em série crescente de alcoóis (30-100\%), secas ao ponto crítico no aparelho $\mathrm{EMS}^{\circledR}{ }^{\circledR} 850$, metalizadas com átomos de ouro em aparelho DESK II ${ }^{\circledR}$ (Desk II Deton Vaccun, NJ, EUA) e examina- das ao microscópio eletrônico de varredura JEOL ${ }^{\circledR}$ (JEOL ${ }^{\circledR}$ - JSM 5410 Tokyo, Japão), operando com feixe de elétrons de $15 \mathrm{keV}$, onde, algumas amostras foram documentadas.

\section{RESULTADOS}

Macroscopicamente a cútis das regiões laterais do pescoço e do tórax de pacas machos e fêmeas, ora analisados, apresentava-se revestida por cerdas longas e espessas, implantadas no sentido crâniocaudal, de coloração castanho avermelhadas, com pintas esbranquiçadas organizadas a formar faixas em posição lateral (Fig.1A).

Não se verificou presença de cerdas na cútis da região medial do carpo sendo esta, apenas recoberta por finos pelos (Fig.1B). Quanto à inserção das cerdas, estas se apresentavam arranjadas em grupos de três ou quatro unidades, sendo o espaçamento entre esses grupos, maior do que a distância entre as cerdas de um mesmo grupo (Fig.1C).

À inspeção a olho nu não foi possível observar presença de pelos menores entre, ou mesmo próximo, a estas cerdas. Entretanto, com o auxilio da microscopia eletrônica de varredura, pôde-se notar que entre as cerdas, nestas regiões

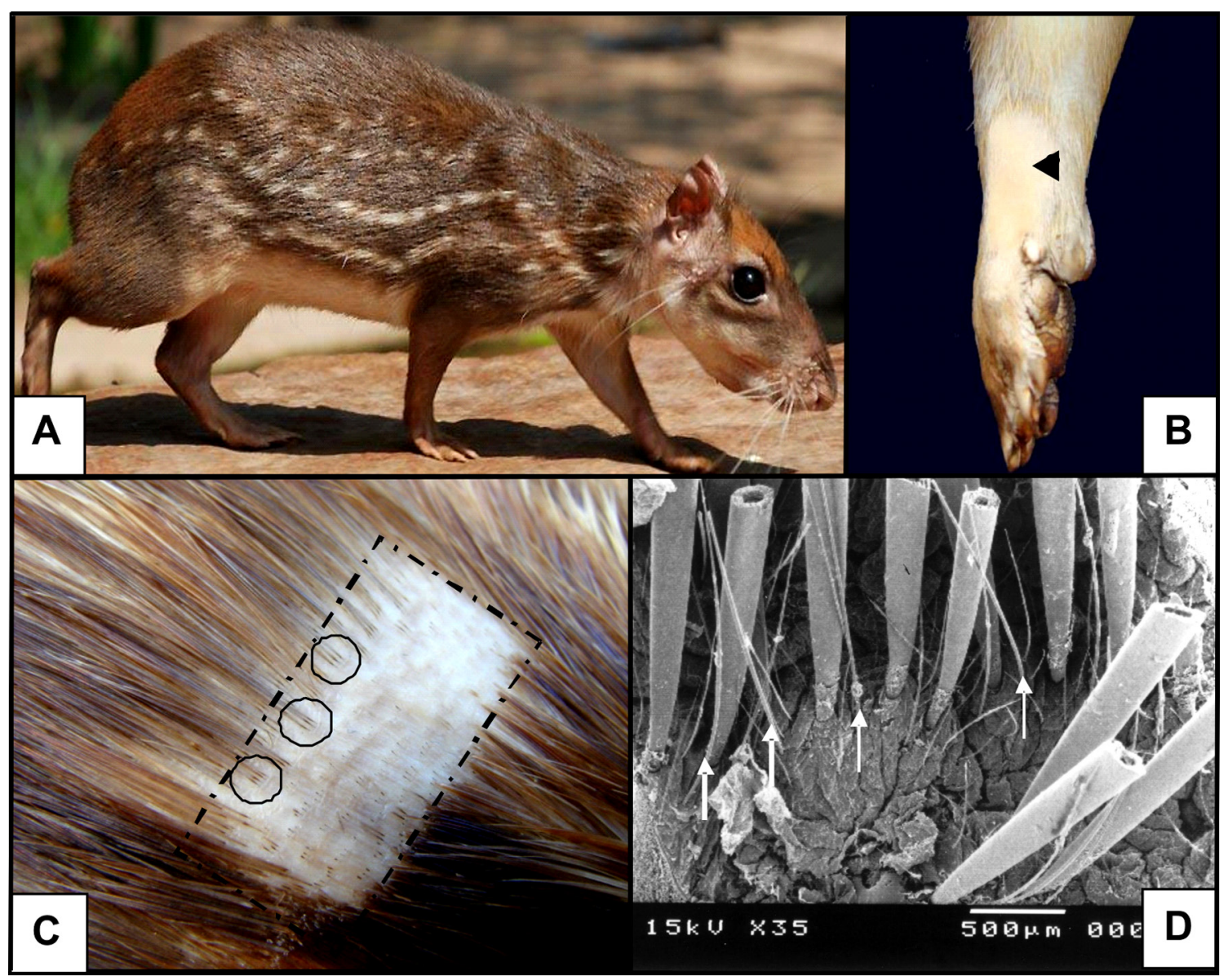

Fig.1. (A) Paca macho adulta com pelagem de coloração castanho avermelhada, com pintas esbranquiçadas organizadas a formar faixas em posição lateral. (B) Região medial do carpo com ausência de cerdas, recoberta apenas por finos pelos (cabeça de seta). (C) A cútis teve uma parte depilada (tracejado) para facilitar a observação do arranjo das cerdas que se apresentavam agrupadas em número de 3 ou 4 (círculo) no sentido crânio caudal do corpo. (D) Eletrofotomicrografia de varredura da cútis da região do tórax de uma paca macho adulta onde se notam as cerdas (de maior espessura) agrupadas em grupos de 3 e pelos finos que existem entre as cerdas do mesmo grupo (setas). 
do tegumento em questão, existiam pelos mais finos e menores entre os grupos de cerdas (Fig.1D).

À microscopia de luz verificou-se que a pele de pacas adultas, tanto machos quanto fêmeas, possuía superfície irregular caracterizando, nas regiões analisadas, diferenças em suas dimensões. Verificou-se ainda, em todas as amostras observadas, que a pele constituía-se de duas camadas: epiderme e derme. Abaixo da derme visibilizou-se a hipoderme e mais profundamente, o tecido muscular (Fig.2A). Tal constituição para a cútis da paca também foi verificada nas amostras observadas à microscopia eletrônica de varredura (Fig.2B).

Histologicamente a epiderme das regiões analisadas apresentava as camadas basal, espinhosa, granular e córnea, evidenciando um tecido epitelial estratificado pavimentoso queratinizado, o qual era formado, em sua maioria, por quatro a seis camadas de células. Na região do carpo, em especial, o número de camadas celulares che- gava a oito. Embora os limites entre as áreas de transição das diferentes camadas fossem evidentes, as camadas bem demarcadas eram a basal, que apresentavam células cúbicas com núcleos esféricos bem corados e a córnea, formada por células pavimentosas típicas, entretanto, a espinhosa e a granulosa eram menos distinguíveis, caracterizando-se como camadas intermediárias (Fig.3A).

Ainda na epiderme verificou-se presença de queratinócitos em todos os estratos, células de Langerhans no estrado espinhoso e melanócitos no estrato basal (Fig.3A). Abaixo da epiderme observou-se em todas as regiões estudadas sob todos os tipos de coloração empregados, a presença de membrana basal, responsável pela separação entre a derme e a epiderme.

Abaixo da membrana basal, foi encontrada a derme papilar ou superficial, composta por uma parte de tecido conjuntivo frouxo, fibras colágenas finas e mais esparsas. Nesta porção foi localizada a grande maioria, senão a totalidade,

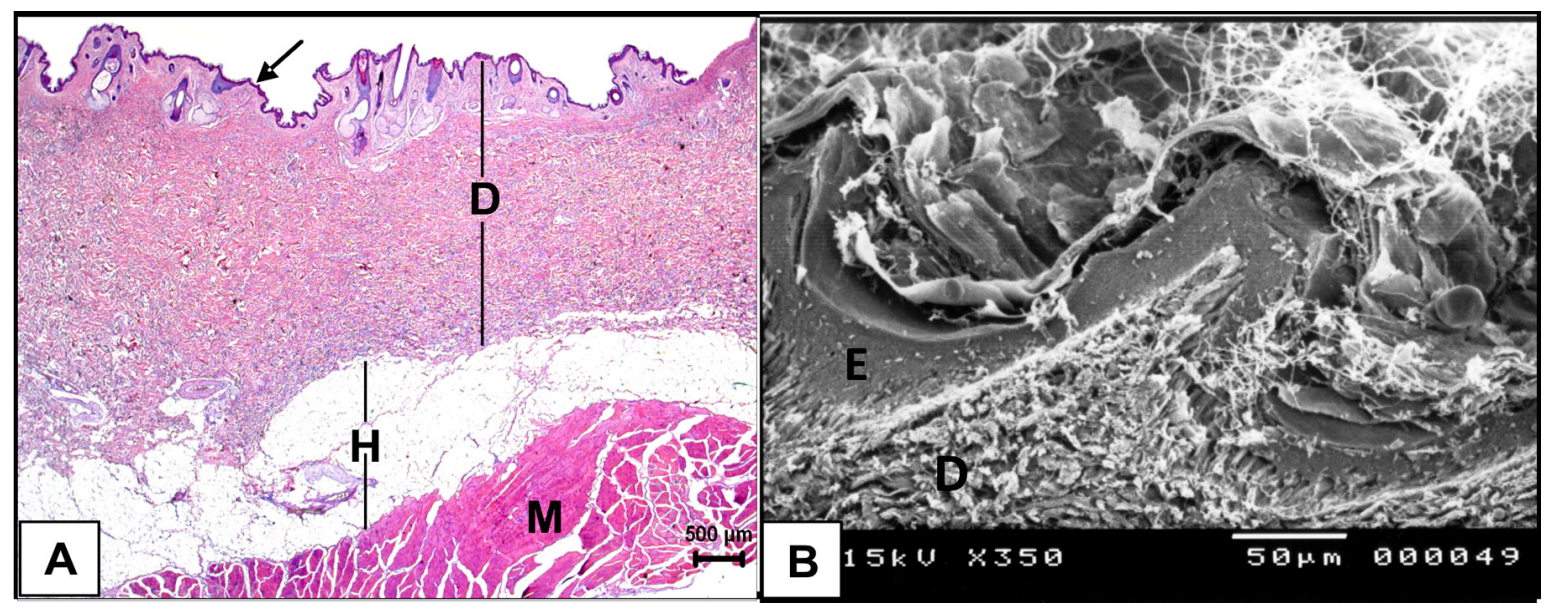

Fig.2. (A) Corte perpendicular do tegumento da região do pescoço esquerdo de paca fêmea, onde é possível distinguir a epiderme (seta), derme (D), hipoderme (H) e tecido muscular (M). HE, 1,6x. (B) Eletrofotomicrografia de varredura da mesma região onde é possível notar a epiderme (E) e a derme (D).

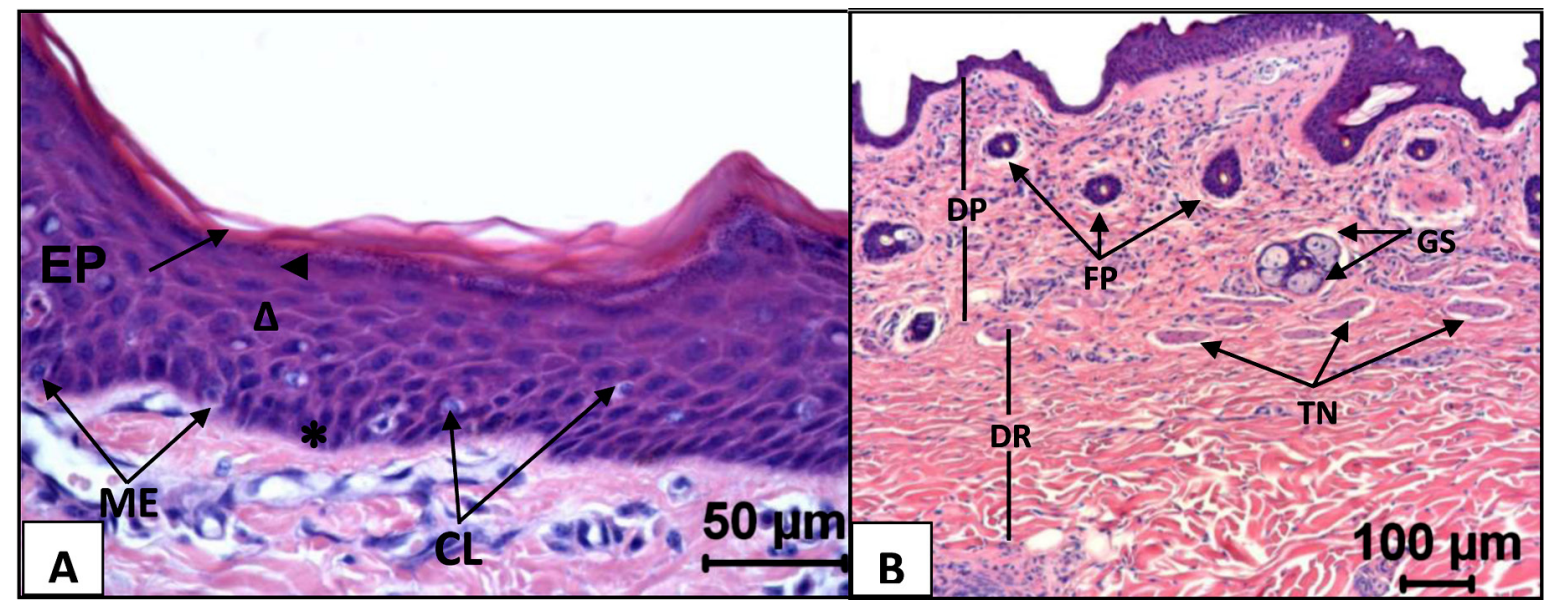

Fig.3. (A) Cútis da região medial do carpo de paca macho adulta em que se verifica na epiderme (EP) nítida camada basal com células cubóides (asterisco), além da camada córnea, com células anucleadas e pavimentosas, bem eosinofílicas (seta); um pouco menos evidente, as camadas espinhosa $(\Delta)$ e a granulosa $(\varangle)$ com células em processo de estratificação e ainda, às células de Langerhans (CL) e melanócitos (ME). HE, 40x. (B) Fotomicrografia de corte perpendicular da cútis da região de pescoço de paca macho, onde é possível diferenciar a derme papilar (DP), onde estão presentes a maioria dos folículos pilosos (FP), terminações nervosas (TN) e glândulas sebáceas (GS) e a derme reticular (DR), composta em sua maioria por colágeno e vasos. HE, 10x. 




Fig.4. (A,B) Fotomicrografia de Luz, HE, 40x, e (C,D) eletrofotomicrografia de varredura de corte perpendicular da cútis $(\mathbf{A}, \mathbf{C})$ da região do pescoço de paca macho e $(\mathbf{B}, \mathbf{D})$ medial do carpo, ilustrando a diferença entre a espessura das fibras de colágeno da derme reticular quando comparadas ao mesmo tamanho de aumento (barras e setas).

da presença dos folículos pilosos, glândulas sebáceas e ainda a presença de grande quantidade de vasos sanguíneos, capilares e terminações nervosas livres como ilustrado na Figura 3B.

As fibras de colágeno da porção da derme reticular das regiões cervical e torácica de pacas macho e fêmea, à observação pela microscopia de luz e de varredura, eram aparentemente maiores e em menor número do que as mesmas fibras encontradas na região medial do carpo desses animais, como pode ser comprovado pela Figura 4.

À observação microscópica de luz e eletrônica de varredura, notou-se que as glândulas sebáceas se encontravam em maior parte na derme papilar, sempre próximo a um folículo piloso ou a seu bulbo (Fig.5). Nas glândulas holócrinas sebáceas adjacentes foram evidenciadas células tronco achatadas e periféricas, e células redondas em

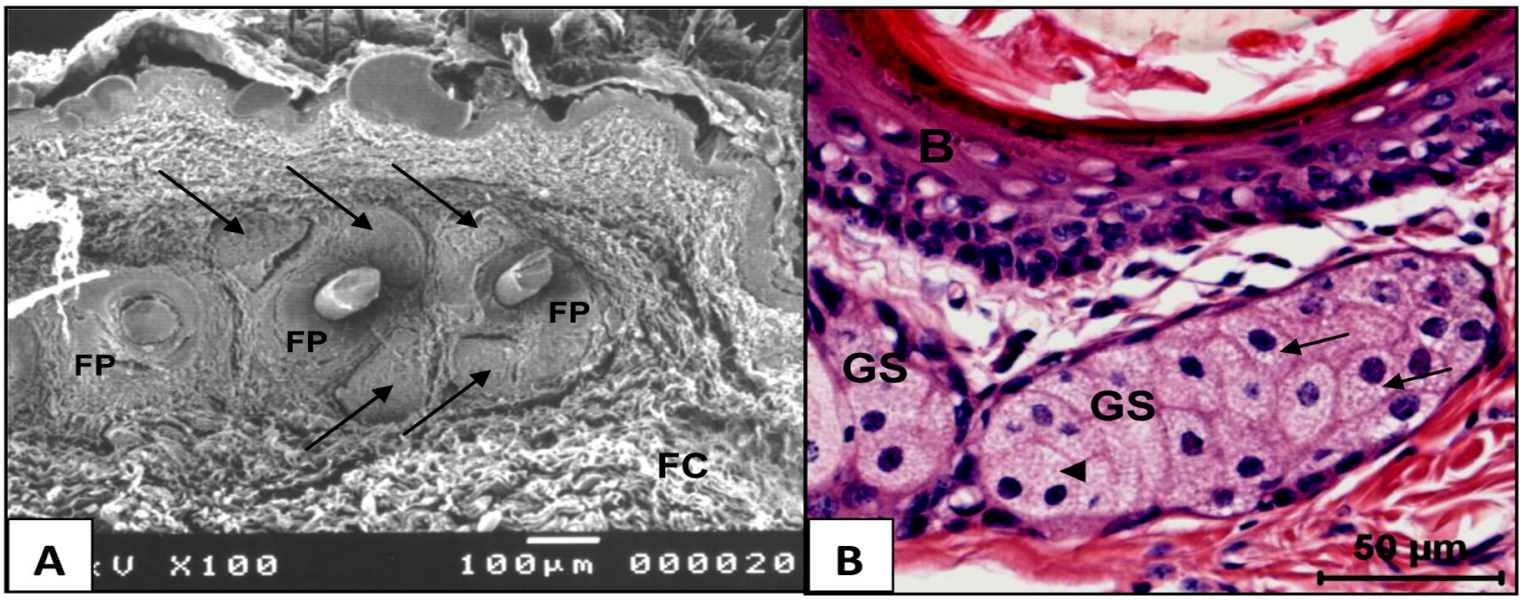

Fig.5. (A) Eletrofotomicrografia de varredura de corte perpendicular da cútis de região torácica de paca macho, em que é possível observar a derme papilar onde estão presentes glândulas sebáceas (setas) sempre próximas aos folículos pilosos (FP) e fibras de colágeno mais finas e esparsas (FC). (B) Fotomicrografia de corte perpendicular da cútis da região de pescoço de paca macho, em que se observa o bulbo de um folículo piloso (B) e glândulas sebáceas (GS) em sua base. Observar que as glândulas repletas de secreção apresentavam-se escuras (seta); as glândulas com pouco conteúdo eram mais claras (४). HE, 40x. 
Quadro 1. Valores ( $\mu \mathrm{m})$ da média, desvio padrão e intervalo de confiança a 95\%, do tamanho da epiderme das regiões do pescoço, tórax e carpo de pacas machos e fêmeas

\begin{tabular}{lcccccc}
\hline & $\begin{array}{c}\text { Pescoço } \\
\text { Macho }\end{array}$ & $\begin{array}{c}\text { Pescoço } \\
\text { Fêmea }\end{array}$ & $\begin{array}{c}\text { Tórax } \\
\text { Macho }\end{array}$ & $\begin{array}{c}\text { Tórax } \\
\text { Fêmea }\end{array}$ & $\begin{array}{c}\text { Carpo } \\
\text { Macho }\end{array}$ & $\begin{array}{c}\text { Carpo } \\
\text { Fêmea }\end{array}$ \\
\hline Média & 36,82 & 31,20 & 37,11 & 32,78 & 49,79 & 40,09 \\
Desvio Padrão & $\pm 4,57$ & $\pm 3,80$ & $\pm 4,87$ & $\pm 3,59$ & $\pm 3,71$ & $\pm 3,22$ \\
Intervalo de & 36,18 & 30,67 & 36,46 & 32,28 & 49,47 & 48,64 \\
confiança a 95\% & - & - & - & - & - & - \\
& 37,45 & 31,73 & 37,79 & 33,28 & 50,51 & 49,54
\end{tabular}

amadurecimento com o citoplasma vacuolizado. As regiões do pescoço, tórax e medial do carpo de pacas machos e fêmeas, apresentavam número e tamanho de perfis de glândulas sebáceas semelhantes, porém, na região medial do carpo, estes eram bem menores e em maior número quando comparados aos perfis das glândulas das duas outras regiões.

Ainda, em todas as regiões corpóreas analisadas foram observados à microscopia de luz, diversos feixes nervosos nas regiões superficial e profunda da derme reticular e hipoderme.

Quanto a espessura da epiderme, nas regiões cervical,

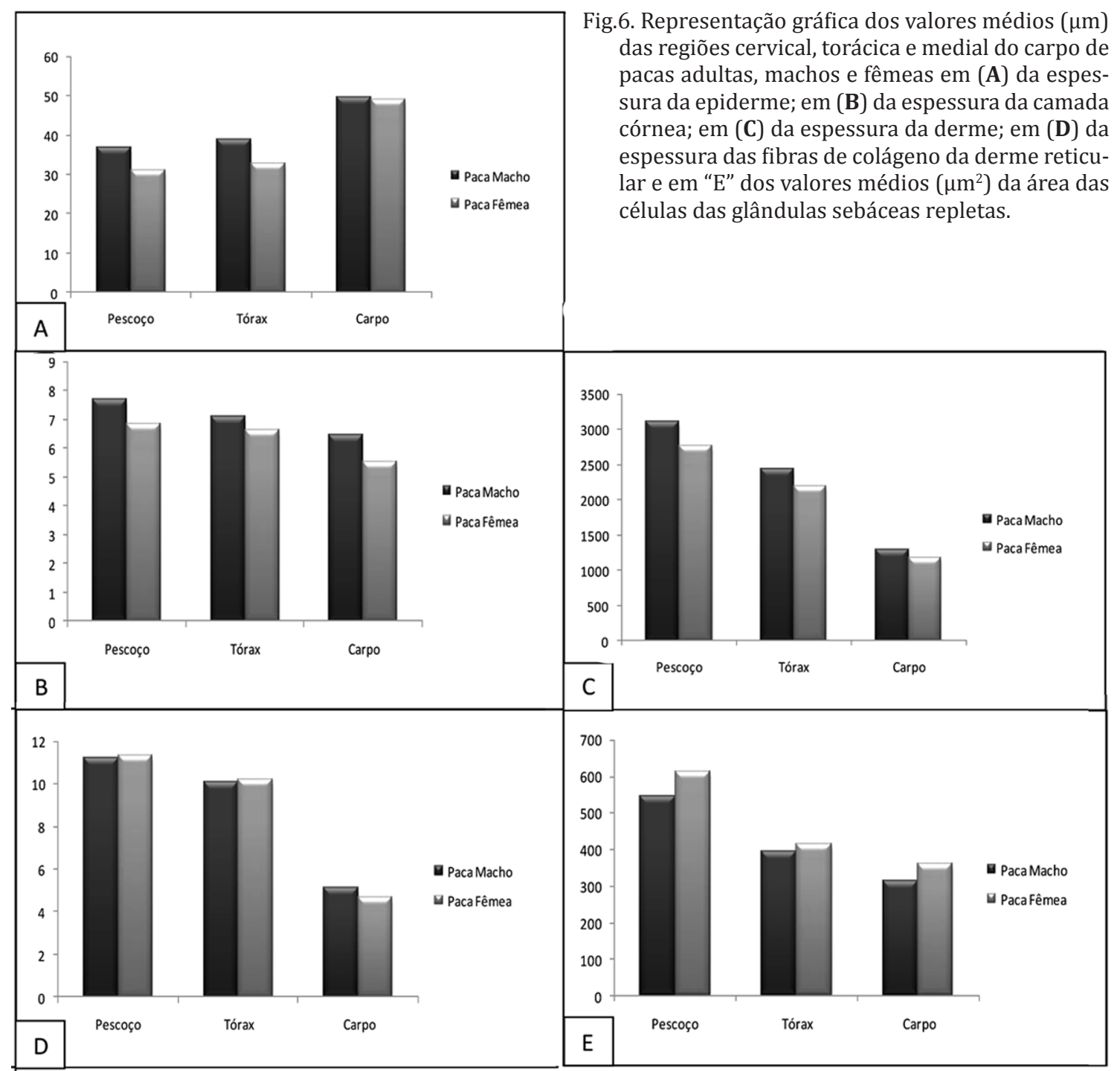

torácica e medial do carpo de pacas adultas, machos e fêmeas, constatou-se, como apresentado no Quadro 1 e na Figura 6A, que os machos possuem a epiderme das regiões cervical e torácica significativamente $(\mathrm{p}<0,001)$ mais espessa do que as fêmeas, entretanto, essa diferença de espessura da epiderme na região medial do carpo, não foi significativa $(p=0,411)$ entre machos e fêmeas. Constatou-se também, que a espessura da mesma variável aumenta significativamente $(\mathrm{p}<0,001)$ em tamanho, da região cervical em direção à torácica. Particularmente à região medial do carpo, esse valor é significativamente $(\mathrm{p}<0,001)$ maior do que os das outras regiões corpóreas analisadas.

Quanto a espessura da camada córnea, constatou-se, como apresentado no quadro 2 e na figura $6 \mathrm{~B}$, que os machos possuem essa camada significativamente $(p<0,001)$ mais espessa do que as fêmeas e que essa espessura diminui também significativamente $(\mathrm{p}<0,001)$ em tamanho, da região cervical em direção à torácica. Particularmente à região medial do carpo, esse valor é significativamente $(p<0,001)$ menor do que os das outras regiões corpóreas analisadas.

Como apresentado no quadro 3 e na Figura 6C, a derme

Fig.6. Representação gráfica dos valores médios $(\mu \mathrm{m})$ das regiões cervical, torácica e medial do carpo de pacas adultas, machos e fêmeas em (A) da espessura da epiderme; em (B) da espessura da camada (D) da espessura das fibras de colágeno da derme reticuar e em "E" dos valores médios $\left(\mu \mathrm{m}^{2}\right)$ da área das células das glândulas sebáceas repletas. 
dos machos é significativamente $(\mathrm{p}<0,001)$ mais espessa em relação à das fêmeas e essa espessura diminui significativamente $(p<0,001)$, em tamanho, da região cervical em direção à torácica. Particularmente à região medial do carpo, esse valor é significativamente $(\mathrm{p}<0,001)$ menor do que os das outras regiões corpóreas analisadas.

A espessura dos perfis das fibras de colágeno da derme reticular, como apresentado no Quadro 4 e na Figura 6D, diminui muito pouco, embora significativamente $(p<0,001)$ da região cervical à torácica, entretanto, quando comparadas às fibras da região medial do carpo, estas se apresentam aproximadamente $50 \%$ significativamente $(\mathrm{p}<0,001)$ menores que as das outras regiões corpóreas em questão. 0 tamanho dessas fibras, nas regiões cervical e torácica não difere significativamente $(p<0,001)$ entre machos e fêmeas, entretanto na mesma comparação, há diferença significativa $(\mathrm{p}<0,001)$ na região medial do carpo.

Quadro 2. Valores $(\mu \mathrm{m})$ da média, desvio padrão e intervalo de confiança a 95\%, do tamanho da camada córnea das regiões do pescoço, tórax e carpo de pacas machos e fêmeas

\begin{tabular}{lcccccc}
\hline & $\begin{array}{c}\text { Pescoço } \\
\text { Macho }\end{array}$ & $\begin{array}{c}\text { Pescoço } \\
\text { Fêmea }\end{array}$ & $\begin{array}{c}\text { Tórax } \\
\text { Macho }\end{array}$ & $\begin{array}{c}\text { Tórax } \\
\text { Fêmea }\end{array}$ & $\begin{array}{c}\text { Carpo } \\
\text { Macho }\end{array}$ & $\begin{array}{c}\text { Carpômea } \\
\text { Fêmea }\end{array}$ \\
\hline Média & 7,73 & 6,86 & 7,13 & 6,66 & 6,49 & 5,64 \\
Desvio Padrão & $\pm 1,56$ & $\pm 1,36$ & $\pm 1,29$ & $\pm 1,12$ & $\pm 1,09$ & $\pm 0,70$ \\
Intervalo de & 7,52 & 6,67 & 6,95 & 6,51 & 6,34 & 5,54 \\
confiança a 95\% & - & - & - & - & - & - \\
& 7,95 & 7,05 & 7,31 & 6,82 & 6,65 & 5,74
\end{tabular}

Quadro 3. Valores $(\mu \mathrm{m})$ da média, desvio padrão e intervalo de confiança a $95 \%$, do tamanho da derme das regiões do pescoço, tórax e carpo de pacas machos e fêmeas

\begin{tabular}{|c|c|c|c|c|c|c|}
\hline & $\begin{array}{c}\text { Pescoço } \\
\text { Macho }\end{array}$ & $\begin{array}{c}\text { Pescoço } \\
\text { Fêmea }\end{array}$ & $\begin{array}{l}\text { Tórax } \\
\text { Macho }\end{array}$ & $\begin{array}{l}\text { Tórax } \\
\text { Fêmea }\end{array}$ & $\begin{array}{l}\text { Carpo } \\
\text { Macho }\end{array}$ & $\begin{array}{l}\text { Carpo } \\
\text { Fêmea }\end{array}$ \\
\hline & & & & 21 & & \\
\hline & & & & & & \\
\hline & 3073,90 & 2742,60 & 2408,40 & 2197,10 & 1273,50 & 60,80 \\
\hline & - & - & - & - & - & - \\
\hline $5 \%$ & 168,30 & 2793,80 & 2484,70 & 2228,00 & 1301,00 & 1189,20 \\
\hline
\end{tabular}

Quadro 4. Valores $(\mu \mathrm{m})$ da média, desvio padrão e intervalo de confiança à $95 \%$, do tamanho das fibras de colágeno da derme reticular das regiões do pescoço, tórax e carpo de pacas machos e fêmeas

\begin{tabular}{lcccccc}
\hline & $\begin{array}{c}\text { Pescoço } \\
\text { Macho }\end{array}$ & $\begin{array}{c}\text { Pescoço } \\
\text { Fêmea }\end{array}$ & $\begin{array}{c}\text { Tórax } \\
\text { Macho }\end{array}$ & $\begin{array}{c}\text { Tórax } \\
\text { Fêmea }\end{array}$ & $\begin{array}{c}\text { Carpo } \\
\text { Macho }\end{array}$ & $\begin{array}{c}\text { Carpo } \\
\text { Fêmea }\end{array}$ \\
\hline Média & 11,24 & 11,36 & 10,12 & 10,23 & 5,13 & 4,68 \\
Desvio Padrão & $\pm 1,50$ & $\pm 1,64$ & $\pm 1,16$ & $\pm 1,15$ & $\pm 0,88$ & $\pm 0,84$ \\
Intervalo de & 11,08 & 11,13 & 9,96 & 10,07 & 5,55 & 4,50 \\
confiança a 95\% & - & - & - & - & - & - \\
& 11,45 & 11,59 & 10,28 & 10,39 & 5,75 & 4,69
\end{tabular}

Quadro 5. Valores $\left(\mu \mathrm{m}^{2}\right)$ da média, desvio padrão e intervalo de confiança a 95\%, da área das células das glândulas sebáceas das regiões do pescoço, tórax e carpo de pacas machos e fêmeas

\begin{tabular}{lcccccc}
\hline & $\begin{array}{c}\text { Pescoço } \\
\text { Macho }\end{array}$ & $\begin{array}{c}\text { Pescoço } \\
\text { Fêmea }\end{array}$ & $\begin{array}{c}\text { Tórax } \\
\text { Macho }\end{array}$ & $\begin{array}{c}\text { Tórax } \\
\text { Fêmea }\end{array}$ & $\begin{array}{c}\text { Carpo } \\
\text { Macho }\end{array}$ & $\begin{array}{c}\text { Carpo } \\
\text { Fêmea }\end{array}$ \\
\hline Média & 546,41 & 614,93 & 395,94 & 415,17 & 313,81 & 360,57 \\
Desvio Padrão & $\pm 27,91$ & $\pm 116,79$ & $\pm 79,14$ & $\pm 71,10$ & $\pm 46,83$ & $\pm 50,51$ \\
Intervalo de & 528,50 & 598,64 & 384,91 & 405,25 & 307,28 & 353,52 \\
confiança a 95\% & - & - & - & - & - & - \\
& 564,25 & 631,21 & 406,98 & 320,08 & 320,34 & 367,61
\end{tabular}

Quanto à área dos perfis das células das glândulas sebáceas, nas regiões estudadas, constatou-se, como apresentado no Quadro 5 e na Figura 6E, que as fêmeas possuem $a$ área desses perfis celulares significativamente $(\mathrm{p}<0,001)$ maiores do que os machos e que esse valor diminui significativamente $(\mathrm{p}<0,001)$, da região cervical em direção à torácica. Particularmente à região medial do carpo, o valor é significativamente $(\mathrm{p}<0,001)$ menor do que os das outras regiões corpóreas analisadas.

\section{DISCUSSÃO}

A pelagem das pacas compunha-se de pelos bem rígidos com características de cerdas. Este atributo é peculiar de alguns roedores e embora não ofereça proteção suficiente contra os predadores, protege o animal da chuva e promove tanto isolamento térmico quanto impermeabilidade (Lekagul \& McNeely 1977). Em todos os animais estudados nesta oportunidade, a organização da pelagem se dá em grupos de três a quatro cerdas, características estas, iguais às descritas por Glover (1940) para os histricomorfos especialmente para Cuniculus paca.

Não se verificou presença de cerdas na região medial do carpo das pacas, sendo essa região, apenas recoberta por finos e curtos pelos. A coloração do pelame das pacas ora estudadas se apresentava variando do castanho-pardo ao castanho-avermelhado, com faixas laterais, longitudinais, mais claras (Mondolfi 1972, Silva 1994).

De modo geral a cútis da paca se estrutura em duas camadas, epiderme e derme, conforme descrições para os mamíferos, na literatura especializada (Banks 1992, Hib 2003, Junqueira \& Carneiro 2008).

Histologicamente a epiderme das regiões do pescoço, tórax e carpo medial, das pacas, apresenta as seguintes camadas: basal, espinhosa, granular e córnea, evidenciando um tecido epitelial estratificado pavimentoso queratinizado, estruturação esta, condizente com os registros existentes para os mamíferos em geral (Banks 1992, Hib 2003, Reis et al. 2008, Souza et al. 2009).

Verificou-se na epiderme das pacas, que as camadas bem demarcadas eram a basal, e a córnea, pois apresentavam sua estrutura como de praxe, descritas para outros mamíferos (Junqueira \& Carneiro 2008). Entretanto, a espinhosa e a granulosa eram menos distinguíveis, diferenciando-se das afirmativas encontradas em alguns tratados clássicos de histologia (Banks 1992, Hib 2003, Souza et al. 2009).

$\mathrm{Na}$ epiderme de todas as regiões analisadas nesta oportunidade, verificou-se presença predominante de queratinócitos, ocorrência de células de Langerhans, as quais, em sua maioria, encontravam-se na camada espinhosa, além de melanócitos, cujos corpos celulares se localizavam no estrato basal (Hib 2003, Junqueira \& Carneiro 2008, Souza et al. 2009).

Abaixo da epiderme observou-se a presença de membrana basal em todas as preparações histológicas das regiões do pescoço, do tórax e medial do carpo, assim como se verifica na cútis dos mamíferos em geral (Banks 1992, Hib 2003).

Relativamente à derme da cútis observou-se nas regiões analisadas das pacas a presença da derme papilar e da re- 
ticular, cada uma delas com seus respectivos componentes (Hib 2003, Junqueira \& Carneiro 2008), embora para Banks (1992), o limiar entre essas duas camadas dérmicas é muito tênue e no caso de ratos essa delimitação praticamente inexiste (Santos et al. 2006).

Foram encontradas no tegumento das pacas glândulas sebáceas nas regiões do pescoço, do tórax e medial do carpo e na maioria das vezes, essas glândulas se localizavam na derme papilar, sempre próximo a um folículo piloso ou ao seu bulbo, à semelhança do que foi descrito para o tegumento de outros mamíferos (Hib 2003, Reis et al. 2008, Souza et al. 2009).

Assemelhando-se, em parte, com as observações de Klauer et al. (1997) que não encontraram glândulas sudoríparas na região de cabeça de roedores escavadores e em concordância com as descrições de Pereira et al. (1980) sobre a capivara, ao relatarem que esses roedores são os únicos a apresentarem glândulas sudoríparas na região da pele coberta por pelos, na paca não se observou este anexo cutâneo em quaisquer das regiões pilosas analisadas. Talvez a pelagem característica de certos roedores (Lekagul \& McNeely 1977), inclusive da própria paca, seja a causa da ausência de glândulas sudoríparas em seu tegumento.

Foram observados ainda, à microscopia de luz, diversos feixes nervosos nas regiões superficial e profunda da derme reticular da paca e também na hipoderme, tal qual acontece nos mamíferos em geral (Hib 2003, Junqueira \& Carneiro 2008).

Comparando-se os resultados morfométricos das variáveis referentes às regiões cervical, torácica e medial do carpo, analisadas entre machos e fêmeas de pacas, verificou-se que os machos apresentam espessura da camada córnea e da derme de todas as regiões avaliadas, além da espessura da epiderme das regiões cervical e torácica, bem como a espessura dos perfis das fibras de colágeno da derme reticular da região medial do carpo, significativamente maiores $(\mathrm{p}<0,001)$ do que as das fêmeas. Azzi et al. (2005) também relataram que a cútis de homens é mais espessa que a das mulheres, assim como Yabuki et al. (2007) observaram que a epiderme da região medial da coxa, nos "miniature pig" machos, apresentava-se mais espessa do que nas fêmeas

De acordo com Azzi et al. (2005) entre os componentes da pele há uma série de estruturas andrógeno-sensitivas e os hormônios esteróides além de influenciarem na espessura da pele, exercem efeitos específicos em suas diferentes camadas e em seus anexos.

Embora se tenha constatado que o valor médio da área dos perfis das células das glândulas sebáceas, repletas de secreção, nas fêmeas de paca, era significativamente $(\mathrm{p}=0,000)$ maior, quando comparado ao dos machos, não se pode afirmar que há maior produção de sebo nas fêmeas, pois é necessário a realização de análises quantitativas específicas, tanto no que se refere à área glandular, quanto à quantidade de glândulas para complementarem essas informações. Entretanto, é possível atribuir tal situação à presença de progesterona, já que este hormônio estimula a secreção sebácea em ratas (Shuster et al. 1977).

Constatou-se também, na paca, que tanto a espessura da camada córnea e da derme, quanto a espessura dos per- fis das fibras de colágeno da derme reticular e ainda que a área dos perfis das células repletas das glândulas sebáceas, aumentam significativamente $(\mathrm{p}<0,001)$, em tamanho, da região cervical em direção à torácica e da torácica em direção à região medial do carpo, em concordância às colocações de Mayer (1952) e Montagna (1967) sobre a possibilidade de haver diferenças na arquitetura da pele, mesmo em um mesmo animal, dependendo das regiões corpóreas estudadas.

Particularmente à espessura da epiderme, nas pacas, esta se apresenta mais espessa na região cervical do que na torácica, entretanto, na região medial do carpo, o valor foi significativamente $(\mathrm{p}<0,001)$ maior do que os das regiões cervical e torácica, provavelmente porque na região medial do carpo não se observaram pelos longos ou mesmo cerdas, e consequentemente, sua epiderme se apresentava mais espessa, tal qual ocorre em regiões corpóreas de outros mamíferos, com pouco revestimento piloso (Hib 2003, Junqueira \& Carneiro 2008).

\section{CONCLUSÕES}

Mediante a metodologia utilizada e os resultados encontrados neste trabalho, pode-se concluir que nas pacas, a arquitetura e coloração de sua pelagem possuem atributos peculiares tal qual ocorrem em alguns roedores.

Seu tegumento apresenta-se histologicamente semelhante ao tegumento dos demais mamíferos em geral, exceto pela ausência de glândulas sudoríparas na região cutânea coberta por pelos.

Mediante análise morfométrica de diferentes regiões do tegumento de machos e fêmeas, pode-se inferir que a arquitetura da cútis desses animais apresenta diferenças quando comparada entre os sexos e também entre as regiões cutâneas de um mesmo animal.

Os machos apresentam espessura da camada córnea e da derme, assim como também a espessura da epiderme das regiões cervical e torácica, além da espessura dos perfis das fibras de colágeno da região medial do carpo, significativamente maiores do que das fêmeas.

As pacas fêmeas apresentam a área dos perfis das células repletas de secreção das glândulas sebáceas maiores do que os machos.

\section{REFERENCIAS}

Albers K.M. \& Davis B.M. 2007. The skin as a neutrophic organ. Neuroscientist 13:371-382.

Azzi L., El-Alfy M., Martel C. \& Labrie F. 2005. Gender differences in mouse skin morphology and specific effects of sex steroids and dehydroepiandrosterone. J. Invest. Dermatol. 124:22-27.

Banks W.J. 1992. Histologia Veterinária Aplicada. $2^{\mathrm{a}}$ ed. Manole, São Paulo, p.629.

Behmer O.A., Tolosa E.M.C. \& Freitas Neto A.G. 1976. Manual de Técnicas para Histologia Normal e Patológica. Edart, SãoPaulo, p.115.

Björkman N., Dantzer V. \& Leiser R. 1989. Comparative placentation in laboratory animals: A review. Scan. J. Lab. Anim. Sci. 16:129-158.

Chuong C.M. \& Homberger D.G. 2003. Development and evolution of the amniote integument: Current landscape and future horizon. J. Exp. Zool. 298:1-11.

Daly T.J.M. \& Buffenstein R. 1998. Skin morphology and its role in ther- 
moregulation in mole-rats, Heterocephalus glaber and Cryptomys hottentous. J. Anat. 193:495-502.

Eisenberg J.F. \& Redford K.H. 1989. Order Rodentia, p.395-397. In: Eisenberg J.F. (Eds), Mammals of the Neotropics: The Northern Neotropics Panama, Colombia, Venezuela, Guyana, Suriname, French Guiana. University of Chicago, Chicago.

Glover M.A. 1940. Hair and scales of the paca. J. Mammal. 21:438-441.

Hamelett W.C. \& Rasweiler IV J.J. 1993. Comparative gestation and placentation in vertebrates. J. Exp. Zool. 266:343-346.

Hib J. 2003. Sistema tegumentar, p.215-233. In: Hib J. (Ed.), Di Fiori Histologia. Guanabara Koogan, Rio de Janeiro.

Junqueira L.C. \& Carneiro J. 2008. Sistema circulatório, p.210-218. In: Junqueira L.C. \& Carneiro J. (Eds), Histologia Básica. Guanabara Koogan, Rio de Janeiro.

Klauer G., Burda H. \& Nevo E. 1997. Adaptive differentiations of the skin of the head in a subterranean rodent, Spalax ehrenbergi. J. Morphol. 233:53-66.

Lekagul B. \& McNeely J.A. 1977. Mammals of Thailand. Association Conservation of Wildlife, Bangkok, 758pp.

Lourenço R.F.S, Dias R.S. \& Gomes A.P.A. 2008. Criação de paca (Agouti paca) como alternativa de diversificação de produção e renda em Minas Gerais. Anais $46^{\circ}$ Congresso da Sociedade Brasileira de Economia, Administração e Sociologia Rural, Rio Branco, AC, p.1-20. (Resumo)

Mayer W.V. 1952. The hair of California mammals with keys to the dorsal guard hairs of California mammals. Am. Midl. Nat. 48:480-512.
Mondolfi E. 1972. La laca o paca. Def. de la Nat. 2:4-16.

Montagna W. 1967. Comparative anatomy and physiology of the skin. Archs Dermatol. 96:357-363.

Pereira N. 1980. The structure of the skin of the capybara. Acta Vet. Venez. 31:361-364.

Reis A.C.G., Martins L.L., Machado M.R.F., Pacheco M.R., Oliveira F.S. \& Agostinho L.C. 2008. Descrição histológica da cútis da região do carpo em cutia criada em cativeiro (Dasyprocta azarae Lichtenstein, 1823). 32 을 Congresso Anual da Sociedade de Zoológico do Brasil, Sorocaba, SP. (Resumo)

Santos M.F.S., Czeczko N.G., Nassif P.A.N., Filho J.M.R., Alencar B.L.F., Malafaia O., Ribas C.A.P.M., Trautwein V.M., Henriques G.S., Maia J.M.A. \& Bittencourt R.C.A. 2006. Avaliação do uso do extrato bruto de Jatropha gossypiifolia L. na cicatrização de feridas cutâneas em ratos. Acta Cirur. Bras. 21:43-49.

Shuster S., Hinkis W.M. \& Thody A.J. 1977. Effect of sex and age at gonadectomy on the sebaceous response to progesterone. J. Endocrinol. 73:67-70.

Silva F. 1994. Mamíferos silvestres do Rio Grande do Sul. 2ª ed. Fundação Zoobotânica do Rio Grande do Sul, Porto Alegre. 264p.

Souza T.M., Fighera R.A., Kommers G.D., Barros C.S.L. 2009. Aspectos histológicos da pele de cães e gatos como ferramenta para dermatopatologia. Pesq. Vet. Bras. 29:177-190.

Yabuki A., Kamimura R., Setoyama K., Tottori J., Taniguchi K., Matsumoto M. \& Suzuki S. 2007. Skin morphology of the claw miniature Pig. Exp. Animal 56:369-373. 